\title{
La subrogación en el sistema de riesgos laborales colombiano*
}

\section{Subrogation in the Colombian workers compensations systems}

\author{
\{ Marco Alejandro Arenas Prada \}**
}

* Recibido: I4 de septiembre de 20I7. Aceptado: 5 de noviembre de 2017.

** Abogado de la Universidad Externado de Colombia, magíster en Derecho Privado de la Universidad de los Andes y especialista en Derecho de Seguros de la Pontificia Universidad Javeriana, en Legislación Financiera de la Universidad de los Andes y en Seguridad Social de la Universidad Externado de Colombia. Profesor de Seguros y Riesgos Laborales de la Universidad Externado de Colombia y de la Pontificia Universidad Javeriana. Actual secretario general de QвE Seguros S.A. DoI: https://doi. org/IO.1860I/25390406.n2.06 


\section{REsumen}

Este trabajo evalúa la figura de la subrogación del asegurador en el Sistema de Riesgos Laborales y aborda de manera crítica sus fundamentos normativos y alcances. Para tal propósito, se analizará el Marco Jurídico Integral, incluyendo las normas que regulan la materia y los más destacados pronunciamientos de las Altas Cortes. El objetivo principal del estudio se centra en sentar una postura frente a la legalidad y viabilidad de la subrogación que ostenta el asegurador frente al tercero causante del daño.

\section{Palabras clave:}

Riesgos laborales; subrogación; asegurador; empleador; tercero responsable; prestaciones.

\section{Abstract}

This paper evaluates the legal basis and scope of subrogation in Colombian Workers Compensation Systems. For that purpose, the comprehensive legal framework will be discussed, including the laws in this area and significant judgments in the field. The main objective of the study is to present the elements to be assessed to Workers Compensations Insurer's subrogation rights before a three party.

\section{KEYWORDS:}

Workers compensations; subrogation; insurer; employer; three party; benefits. 


\section{INTRODUCCIÓN}

La subrogación en seguros de personas, como el de riesgos laborales, es una figura sui generis dentro del ordenamiento jurídico colombiano. En principio, cuando se expidió el Código de Comercio se contempló una posible subrogación del asegurador de riesgos laborales en contra del responsable causante del evento ATEP ${ }^{\mathrm{I}}$, siempre y cuando mediara pacto expreso entre las partes. Esta última condición generó que en la práctica no se lograra materializar la aludida subrogación, por la natural dificultad de concretar un acuerdo en ese sentido.

Solo hasta 1994 se volvió a abordar regulatoriamente esta figura por medio del Decreto I77I, que en su artículo I 2 facultó al Asegurador de Riesgos Laborales (ARL) para repetir en contra del tercer causante del siniestro.

Pese a la aludida norma, la jurisprudencia de la Corte Suprema de Justicia se ha mostrado reacia a darle vigor jurídico a la figura y, en esa medida, ha rehusado reconocer efecto alguno del mencionado decreto y, en consecuencia, de la figura de la subrogación en riesgos laborales, bajo la premisa de que las prestaciones derivadas del sistema de riesgos laborales y la indemnización proveniente de la reparación del daño causado en cabeza del responsable del evento, son perfectamente acumulables en cabeza del trabajador o de sus beneficiarios, según corresponda, lo que, como es natural, inviabiliza una posible subrogación por parte del asegurador que ha honrado sus obligaciones de acuerdo con lo establecido en las normas que regulan el subsistema de riesgos laborales.

$\mathrm{La}$ inconsistencia existente entre las normas vigentes y las posturas de la jurisprudencia del Tribunal de Cierre justifica el presente estudio, que pretende aportar elementos jurídicos para abordar la figura de la subrogación en cabeza del asegurador. En esa medida, el escrito iniciará por esbozar los elementos jurídicos básicos de la figura genérica de la subrogación atribuida por el artículo ı 096 del Código de Comercio al Asegurador y la específica que se consagra para el sistema de riesgos laborales, para luego estudiar de forma crítica la línea que ha sentado la jurisprudencia de la Corte Suprema de Justicia y finalizar con unas conclusiones que articulan el entendimiento tanto de la legislación como de la jurisprudencia en la materia. 


\section{La SUbROGACIÓN EN EL CONTRATO de SEgURO}

\section{FUNDAMENTOS Y ALCANCES DE LA SUBROGACIÓN}

El legislador colombiano ${ }^{2}$ ha dispuesto que la figura de la subrogación opere por ministerio de la ley y aún en contra de la voluntad del acreedor. De acuerdo con lo anterior, el Código de Comercio introdujo un importante cambio en materia de seguros al consagrar en su artículo rog6 la figura de la subrogación, según la cual el asegurador que pague una indemnización se subrogará por ministerio de la ley y hasta la concurrencia del importe de lo indemnizado, en los derechos del asegurado contra el responsable del siniestro.

Teniendo en cuenta que el artículo io96 hace parte del título v, capítulo II del Código de Comercio, que regula los seguros de daños, es claro que la figura de la subrogación es propia de esa modalidad de aseguramiento y no de los seguros de personas, salvo la excepción contemplada en el artículo i ioo de esa misma codificación, que extiende la aplicación de las normas genéricas de la subrogación al seguro de accidentes de trabajo.

El referido artículo ro96 del Código de Comercio modificó el artículo 677 del Código de Comercio Terrestre que consagraba la figura de la cesión de derechos, según la cual, el asegurador podía exigirle al asegurado la cesión de los derechos que ostenta en contra de terceros en virtud del siniestro y como requisito anterior al desembolso de la indemnización.

Sin duda, el instituto de la subrogación desempeña un papel estelar en el derecho de seguros, pues evita que en la práctica ocurran situaciones abiertamente incompatibles con elementales principios jurídicos, tales como que el asegurado, además de recibir la indemnización derivada del contrato de seguro, obtenga la derivada del acto dañoso desplegado por el tercero responsable, lo que claramente pugna con el principio indemnizatorio, según el cual, la parte asegurada no puede lucrarse por la ocurrencia del siniestro, en la medida en que los seguros son un instituto de mera indemnización que buscan, en particular, resarcir los perjuicios y restablecer el equilibrio económico perdido producto de la ocurrencia del siniestro. Asimismo, si no existiera la figura de la subrogación, sería posible que en la práctica el victimario quedara exento de cualquier sanción o deber de resarcimiento por la sola existencia del contrato de seguro.

Sin duda, la subrogación es una clara consecuencia del carácter indemnizatorio del seguro de daños, que no opera en el seguro de personas, salvo la ya referida excepción en materia de riesgos laborales. Lo que busca el legislador al 
consagrar el instituto de la subrogación es trasladar la acción contra el responsable del siniestro, en favor de quien paga la indemnización, de manera que este pueda perseguir al responsable; situación que no deja de causar alguna inquietud en el común de las gentes, quienes, bajo una lógica económica, consideran que el asegurador que recibe la prima no debería, entre otras cosas, pedir el reembolso del siniestro ante el responsable de este.

Pues bien, frente a este argumento, debe anotarse que en todas las legislaciones del mundo y, en especial, en las continentales, es común establecer un mecanismo jurídico para trasladarle al asegurador las acciones del asegurado contra el responsable del siniestro y una de las más importantes razones de política legislativa que sustenta la subrogación es, precisamente, el principio de no enriquecimiento sin causa, de manera que el asegurado como víctima del hecho dañoso reciba una indemnización integral de los perjuicios padecidos y que, a su turno, el responsable del siniestro no quede impune. Además, desde el punto de vista técnico, los recobros que adelantan las compañías de seguros por medio de la acción en subrogación forman parte de los factores que inciden en la fijación de las tarifas, razón por la cual, en aquellos eventos en los que la aseguradora no tiene opción de recobro, la tarifa tiende a ser superior.

Por lo anterior, y en aras de preservar la efectividad del instituto de la subrogación, el Estatuto Mercantil, por una parte, le exige al asegurado hacer todo lo que esté a su alcance para facilitar el ejercicio de la acción de subrogación, so pena de que el asegurador pueda deducir de la indemnización el valor de los perjuicios que cause dicha falta de cooperación y, por otra, le prohíbe de manera expresa desplegar cualquier acto jurídico o material que pueda entorpecer el ejercicio de la acción de subrogación que ostenta el asegurador, advirtiendo que en el evento que renuncie a los derechos que le asisten frente al victimario, este perderá el derecho a la indemnización.

Como se anotó antes, el asegurador solo podrá accionar en contra del tercero causante del daño en ejercicio de la acción de subrogación hasta por el importe de lo pagado a título de indemnización, lo que impide que este pueda perseguir cualquier suma adicional, como intereses moratorios, remuneratorios, deducibles, entre otros. Sin embargo, a partir del 2005, la jurisprudencia de Sala de Casación Civil de la Corte Suprema de Justicia ${ }^{3}$ aceptó que, en ejercicio de la acción de subrogación, el asegurador pueda exigirle al victimario el pago de la suma indemnizada debidamente indexada, bajo el entendido que al aplicar corrección monetaria sobre el valor de la indemnización, la aseguradora subrogada no está recibiendo una suma superior al importe de lo pagado, pues dicha actua- 
lización surge como consecuencia del reconocimiento de la connatural pérdida de poder adquisitivo que sufre el dinero por el paso del tiempo.

En opinión de la Corte, al indexar el valor de la indemnización se está preservando el poder liberatorio de la moneda, bajo el entendido de que la corrección monetaria hace parte del concepto "importe" que consagra el artículo rog6 del Código de Comercio y, en esa medida, si no se indexara se estaría generando un enriquecimiento injustificado en favor del tercero causante del daño, quien a la postre terminaría pagándole al asegurador una cifra que económicamente es inferior a la que sufragó este último cuando honró la obligación indemnizatoria derivada del contrato de seguro.

Como se puede ver, la subrogación se deriva del pago válido efectuado por el asegurador al asegurado. Sin embargo, debe precisarse que no se trata del pago de una obligación ajena, en otras palabras, el asegurador al pagar la indemnización no está asumiendo una obligación que realmente le corresponde al causante del daño, todo lo contrario, al efectuar el pago, el asegurador está honrando una obligación propia y, en virtud de dicho pago, puede repetir en contra de un tercero.

\section{EL EJERCICIO DE LA ACCIÓN SUBROGATORIA}

Pese a que la redacción del artículo rog6 del Código de Comercio pareciera sugerir que el único requisito para ejercer la acción de subrogación consiste en haber pagado la indemnización y que, adicionalmente, el ejercicio de la acción respectiva está limitado al importe de lo pagado; para que el pago efectuado por el asegurador genere en cabeza de este el derecho a subrogarse en contra del tercero, será necesario que dicho pago haya sido válido a la luz del contrato de seguro.

En esa medida, cuando el asegurador efectúa pagos que no se ajustan técnica ni jurídicamente a los términos previstos en la póliza, no será viable que ejerza la acción de subrogación. Lo anterior implica, como es razonable, que el daño padecido por el asegurado, en efecto, haya estado cubierto o amparado por la póliza y que, además, una vez ocurrido el siniestro, surja para el asegurado una acción de responsabilidad en contra del tercero.

Ahora bien, teniendo en cuenta que la acción de subrogación que ejerce el asegurador es la misma que ostentaba el asegurado frente a su victimario, este último, además de proponerle al asegurador las mismas excepciones que habría podido proponerle al asegurado, podrá alegar a su favor la falta de calidad de asegurador de quien pagó la indemnización, así como, la falta de coincidencia entre el asegurado a quien se pagó la indemnización y la persona a quien el causante del siniestro está obligado a responder. Frente a ese particular, resulta ilustrativa 
la sentencia del 22 de enero de I99I proferida por la Corte Suprema de Justicia, que de manera clara amplió el abanico de excepciones que puede proponerle el tercero al asegurador subrogado ${ }^{4}$.

Otro importante asunto a destacar, y que genera una clara limitación a la facultad de subrogación que ostenta el asegurador, se presenta cuando la parte pasiva de la acción es el mismo asegurado o uno de sus parientes en línea directa o colateral dentro del segundo grado, salvo que estos hayan actuado de manera dolosa o gravemente culposa. De lo anterior, se colige que la subrogación en los seguros de responsabilidad está proscrita, excepto en los casos en los que medie dolo o culpa grave del asegurado.

Es así como, al ser la acción de subrogación la misma que ostentaba el asegurado frente al tercero responsable del daño, el régimen jurídico y el término de prescripción que gobierna la acción de subrogación es el mismo al que está sujeta la acción indemnizatoria de la que era titular el asegurado perjudicado contra el victimario y, en ese orden, el régimen de prescripción dispuesto por el artículo ro8 I del Código de Comercio no tiene aplicación alguna en el marco de la acción de subrogación, pues, en estricto sentido, esta última no se deriva, propiamente, del contrato de seguro, sino de la relación de responsabilidad que ata al asegurado (víctima) con el tercero (victimario).

\section{LOS CONTRATOS DE CESIÓN Y LA SUBROGACIÓN}

Antes de la expedición del actual Código de Comercio, la celebración de contratos de cesión de derechos era una práctica tan arraigada en el sector asegurador, que incluso con posterioridad a I97 I los aseguradores continuaban celebrando dichas cesiones. Ello generó un pronunciamiento de especial relevancia en esta materia por parte de la Sala de Casación Civil de la Corte Suprema de Justicia ${ }^{5}$, por medio del cual el Alto Tribunal señaló que, si bien, el Código de Comercio Terrestre admitía la figura de la cesión de derechos, desde la expedición del nuevo estatuto mercantil impera el instituto de la subrogación legal que tiene un carácter indisponible para las partes. Así mismo, la Corte señaló que los contratos de cesión de derechos se encuentran por fuera del espectro del objeto social de las aseguradoras, agregando que estas incurren en una conducta constitutiva de fraude a la ley cuando celebran esa clase de negocios jurídicos y además, el asegurador que celebre un contrato de cesión por cualquier valor

4 Colombia, Corte Suprema de Justicia, Sala de Casación Civil, Sentencia (22 de enero de r99i), M.P.: Eduardo García Sarmiento.

5 Colombia, Corte Suprema de Justicia, Sala de Casación Civil, Sentencia (23 de septiembre de i993), M.P.: Pedro Lafont Pianetta. 
que exceda el importe del pago de la indemnización estará violando el principio indemnizatorio.

En mi opinión, el concepto de la Corte es válido, en cuanto a la eficacia de la figura de la subrogación y no de la cesión de derechos una vez expedido el Código de Comercio de r97 I. Sin embargo, estimo excesiva la postura del Alto Tribunal, según la cual los aseguradores no pueden celebrar cesiones de derechos sobre sumas diferentes al valor de la indemnización.

Sin duda, pretender seguir aplicando la figura de la cesión de derechos sobre el importe de lo pagado es abiertamente contrario a la ley, teniendo en cuenta que el artículo ro96 del Código de Comercio es una norma imperativa que no puede ser modificada por las partes, pero lo que estimo un exceso es que la Corte haya proscrito la celebración de cesiones de derechos sobre sumas diferentes al importe de lo pagado, básicamente por las siguientes razones:

i) Pretender extender el alcance del principio indemnizatorio al asegurador, a mi juicio, es un argumento risible que además va en contravía de la ley.

De la lectura del artículo ro88 del Código de Comercio se desprende con total claridad que el principio indemnizatorio, según el cual los contratos de seguros de daños serán de mera indemnización y no pueden constituir fuente de enriquecimiento, se aplica únicamente al asegurado y no al asegurador. Ello se desprende no solo del texto de la norma, sino, en particular, de la dinámica económica del seguro, pues se presenta como un contrasentido signar el carácter indemnizatorio al asegurador, ya que a diferencia del asegurado, el asegurador sí puede lucrarse del contrato de seguro. Es más, el fin último del asegurador es obtener un provecho económico, de manera que pretender extender el principio indemnizatorio al asegurador y por esa vía proscribir que este celebre un negocio jurídico de cesión sobre valores diferentes al importe de la indemnización es una postura carente de fundamento jurídico y económico, de la que me aparto por completo.

ii) La afirmación según la cual el objeto social de las aseguradoras no permite la celebración de contratos de cesión, a mi juicio resulta por lo menos ligera, teniendo en cuenta que, si se trata de valores relacionados con el perjuicio padecido por el asegurado con ocasión del siniestro, $v . g r$. el valor del deducible o el defecto en la suma asegurada derivado del infraseguro, la celebración de una cesión de derechos podría considerarse como una actividad conexa al objeto social de la aseguradora y, en esa medida, claramente podría celebrarse bajo la legislación colombiana, siempre y cuando, el contrato de cesión se celebre a título oneroso entre el asegurador y el asegurado.

Además, nada obsta para que dentro del objeto social de una compañía de seguros se incluya la celebración de cesiones de derechos con los asegurados sobre valores diferentes del importe de la indemnización pagada y que corres- 
pondan a la parte de los perjuicios padecidos por el asegurado y no cubiertos por la póliza.

Todo lo anterior, sin perder de vista que la postura de la Corte comporta una limitación inaceptable a la autonomía negocial y además es innegable que la celebración de una cesión de derechos sobre las sumas que (haciendo parte de la indemnización integral a que tiene derecho la víctima) exceden el valor pagado por el asegurador, facilita que en la práctica el responsable del siniestro indemnice integralmente los perjuicios causados al asegurado, toda vez que, como se anotó previamente, es perfectamente posible que producto del infraseguro, el deducible o cualquier otra circunstancia, el valor indemnizado por el asegurador sea inferior al valor integral de los perjuicios.

Además, resulta contrario a la economía procesal que sea necesario que tanto el asegurador subrogado como el asegurado deban interponer acciones en contra del tercero causante del perjuicio cuando la indemnización pagada por el asegurador es inferior al valor total del perjuicio, pues en esos eventos una cesión celebrada sobre dichos excesos, facilitaría el cobro ante el tercero y disminuiría la congestión de los despachos judiciales.

iii) Hablar de fraude a la ley cuando se celebra una cesión de derechos es una clara impropiedad en la medida que, lo que realmente se materializa cuando el asegurador en lugar de subrogarse celebra una cesión de derechos, es una violación a una norma imperativa, lo que jurídicamente genera unas consecuencias distintas al fraude a la ley alegado por la Corte.

En esa medida, se estima razonable que no se admita una cesión de derechos sobre el importe de lo pagado por el asegurador, pues en ese escenario opera la subrogación dispuesta por el artículo rog6 del Código de Comercio. Sin embargo, nada obsta para que el asegurador celebre con el asegurado una cesión de derechos a título oneroso sobre la diferencia entre el valor de la indemnización derivada del contrato de seguro y el valor de la indemnización integral a cargo del responsable del evento dañoso.

\section{La SUbrogación EN EL SEgURO de RIESGoS LABORALES}

\section{Marco nORMativo}

Como se anotó antes, el artículo ıo96 del Código de Comercio es la norma de la cual dimana la figura de la subrogación en materia de seguros de daños. Por su parte, el artículo i Ioo del mismo estatuto consagra una excepción particular en materia de subrogación, al establecer que en el de riesgos laborales, pese a tratarse de un seguro de personas, es viable que el asegurador se subrogue en contra del causante del daño, siempre y cuando las partes así lo convengan. 
Por otra parte, dentro de las normas que regulan el Sistema General de Seguridad Social, el Decreto I 77 I de I994, reglamentario del Decreto Ley I 295 de i994, establece en el artículo i 2 lo siguiente:

Subrogación. La entidad administradora de riesgos profesionales podrá repetir, con sujeción a las normas pertinentes, contra el tercero responsable de la contingencia profesional, hasta por el monto calculado de las prestaciones a cargo de dicha entidad administradora, con sujeción en todo caso al límite de responsabilidad del tercero.

Lo dispuesto en el inciso anterior no excluye que la víctima, o sus causahabientes, instauren las acciones pertinentes para obtener la indemnización total y ordinaria por perjuicio, de cuyo monto deberá descontarse el valor de las prestaciones asumidas por la entidad administradora de riesgos profesionales. ${ }^{6}$

Curiosamente, el referido artículo I 2 del Decreto I 77 I de I 994 ha concitado un sinnúmero de discusiones frente a su interpretación. En mi opinión, el correcto entendimiento de dicha norma debe partir de un estudio armónico de los preceptos del Código de Comercio que regulan genéricamente la figura de la subrogación en materia de seguros. En esa medida, cuando la norma transcrita indica que la Entidad Administradora de Riesgos Profesionales (hoy Laborales) podrá repetir, con sujeción a las normas pertinentes, está haciendo referencia a que el ejercicio de la subrogación por parte de la ARL depende del cumplimiento de los requisitos estudiados en el capítulo anterior de este artículo. Esto es, debe tratarse de un pago que jurídica y técnicamente sea válido y, en ese orden, no operará cuando se trate de indemnizaciones pagadas por mera conveniencia comercial o ex gracia y, en ningún caso, ejerciendo la acción de subrogación, el asegurador podrá pretender el pago de una suma superior al importe de lo pagado a título de indemnización.

\section{LA PARTE PASIVA DE LA ACCIÓN DE SUBROGACIÓN EN RIESGOS LABORALES}

Otro importante asunto derivado del referido artículo i 2 es el atinente a la determinación de quién o quiénes pueden ser considerados la "parte pasiva" de la acción de subrogación. Como se lee en la norma, la persona contra quien puede ser ejercida la acción de subrogación es "el tercero responsable de la contingencia profesional".

6 Colombia, Presidencia, Decreto (I77 I de 1994), sobre reglamentación parcial del Decreto I 295 de I994, art. I2. 
Pues bien, en mi opinión, la acepción "tercero" debe corresponder a cualquier persona que no esté inmiscuida en la relación de aseguramiento y, en esa medida, no pueden ser considerados como "terceros" ni la parte asegurada ni la parte aseguradora.

Como es sabido, el de riesgos laborales es un seguro sui generis que pertenece al Sistema General de Seguridad Social, razón por la cual, a diferencia de los seguros propiamente mercantiles, en ellos no se celebra un contrato sino una afiliación, que en el caso de los trabajadores dependientes corre por cuenta del empleador quien, en caso no hacerlo, deberá asumir con cargo a su propio peculio las eventuales prestaciones económicas y asistenciales que requieran sus trabajadores.

En ese orden de ideas, estimo razonable considerar que siendo el empleador el que realiza la afiliación y quien tiene a su cargo el pago del ıoo \% de las cotizaciones (primas), este sea considerado como el tomador en el seguro de riesgos laborales y, en esa medida, no pueda ser parte pasiva de la acción de subrogación, en la medida que, no se trata de un tercero en estricto sentido.

Este asunto resulta especialmente relevante, pues en algunas ocasiones el "responsable de la contingencia profesional" es el empleador que ha incurrido en culpa patronal y, en esa medida, en dichos eventos no será viable que el asegurador promueva una acción de subrogación en su contra, teniendo en cuenta que no ostenta la calidad de tercero, tal y como lo exige la norma objeto de análisis.

Adicionalmente, vale la pena resaltar que, el artículo i 2 del Decreto I 77 I de 1994 incluye una variación importante frente al artículo ro96 del Código de Comercio (norma genérica en materia de subrogación), pues en esta última se indica de manera pura y simple que la subrogación operará en contra de las personas responsables del siniestro, mientras que el artículo i 2 del Decreto I 77 I restringe la facultad de subrogación de la ARL en contra de tercero responsable de la contingencia, lo que sin duda genera una importante diferencia. Pues en el escenario del artículo I 2 sería plausible una interpretación según la cual el empleador, por no ser un tercero dentro de la relación de aseguramiento en materia de riesgos laborales, no podría ser parte pasiva de la acción de subrogación, aun cuando sea el responsable del siniestro, como ocurre en todos los casos en los que se comprueba que la negligencia o el dolo del empleador es la causa eficiente del evento dañoso.

\section{La juRisprudencia de la Corte Suprema de Justicia en la materia}

La figura de la subrogación en materia de riesgos laborales se ha visto seriamente impactada, producto de la línea jurisprudencial que ha venido sosteniendo la Corte Suprema de Justicia, por medio de la cual ha negado efectos jurídicos a la 
acción de subrogación que ejercen las administradoras de riesgos laborales, bajo argumentos de los que me aparto.

El primer pronunciamiento de la Corte frente a este asunto data de $199 \mathrm{I}^{7}$. En esa oportunidad, pese a que aún no se había expedido el Decreto i77 I de I994, partiendo de la base de que las prestaciones derivadas del sistema de riesgos laborales son acumulables o descontables de la indemnización integral que debe pagar el empleador que ha incurrido en culpa patronal o el tercero responsable del evento, el Alto Tribunal encontró viable que el asegurador se subrogue sobre el importe de las prestaciones que ha reconocido.

Paradójicamente, la anterior postura ya fue modificada por el Alto Tribunal, en pronunciamientos proferidos durante $1996^{8}$ y 1998 , después de haberse expedido el Decreto I77I de 1994, que en su artículo I 2 consagró de manera expresa el derecho que le asiste al asegurador de riesgos laborales de subrogarse en contra del tercero responsable del evento dañino.

En opinión de la Corte, la causa jurídica de la cual se derivan las prestaciones propias del subsistema de riesgos laborales es completamente diferente a la de la indemnización integral de perjuicios y, en consecuencia, estimó inviable descontar de la indemnización a cargo del responsable del hecho dañoso, los valores correspondientes a las prestaciones pagadas por la ARL, pues en tal caso, se generaría un beneficio en favor de dicho responsable.

A partir de ese planteamiento, la Corte concluyó que era inviable admitir la acción de subrogación ejercida por el asegurador y, en esa medida, negó cualquier posible aplicación del artículo i 2 del Decreto i77 I de I994.

Ese primer pronunciamiento, marcó la senda de una postura sumamente gravosa para la figura de la subrogación, en la medida que en I9989, la Sala Civil de la Corte volvió a pronunciarse reiterando que las prestaciones derivadas del sistema de riesgos laborales son perfectamente acumulables con las indemnizaciones integrales de perjuicios y, en consecuencia, negó la efectividad de dicha figura, dado que, como es natural, al ser acumulables no resulta viable que la ARL le recobre al causante del daño el valor de las prestaciones que ha reconocido, pues esto comportaría una disminución en el valor final de la indemnización que por responsabilidad recibiría el trabajador o sus beneficiarios, según sea el caso.

Como se puede observar, la Corte no le ha dado aplicación a la figura de la subrogación en materia de riesgos laborales, como consecuencia de una postura según la cual las prestaciones derivadas del sistema de riesgos laborales y las

Colombia, Corte Suprema de Justicia, Sala de Casación Civil, Sentencia (3 de septiembre de I99I), M.P.: Pedro Lafont Pianetta.

8 Colombia, Corte Suprema de Justicia, Sala de Casación Civil, Sentencia (24 de junio de I996).

9 Colombia, Corte Suprema de Justicia, Sala de Casación Civil, Sentencia (2 2 de octubre de i 998), M.P.: José Fernando Ramírez Gómez. 
indemnizaciones de perjuicios son perfectamente acumulables, por provenir de causas jurídicas distintas, pese a que, como es evidente, en realidad se generan por un mismo evento ATEP y, en cualquier caso, como será expuesto más adelante, la Corte rompe de un tajo con el principio indemnizatorio, dándole un alcance completamente inapropiado y permitiendo que por un mismo evento el asegurado perciba una doble indemnización que genera un evidente incremento a su patrimonio económico y no el mero restablecimiento, tal y como lo ordena el principio indemnizatorio.

Luego, en el 2000, la Corte cambió la línea argumentativa e indicó que el factor determinante para establecer la procedencia de la subrogación en favor de la ARL radica en determinar si las prestaciones reconocidas por el Sistema General de Riesgos Laborales tienen carácter indemnizatorio ante lo cual, la Corte concluyó que no lo tienen debido a que el empleador ha hecho una cotización previa y en esa medida resulta inviable que el asegurador se subrogue.

Frente al particular, la Corte indicó que:

Ante todo y a este propósito, es indispensable definir si la pensión de sobrevivientes tiene carácter indemnizatorio, por ser ése el supuesto en el que se asienta la subrogación. En tal orden de ideas, para la Corte es claro que la indicada prestación social de carácter económico, no tiene aquella connotación, como se deduce de considerar que, cual lo afirma la Sala Laboral de esta Corporación, ella '... cubre el riesgo de la muerte del asegurado bien sea trabajador activo o pensionado, en beneficio fundamentalmente de los integrantes de la familia de este (Acuerdo 049 de I990, art. 27) pues es de presumir que ellos se verán privados del ingreso que les permitía mantener un determinado nivel de vida, al paso que la pensión de vejez cubre el riesgo generado por la presunta pérdida de la capacidad de trabajo en razón de la edad y permite al asegurado dejar de trabajar sin perder del todo su ingreso ... De otra parte, la pensión de sobrevivientes en modo alguno es gratuita, sino al contrario, solo surge previo el pago más o menos prolongado de cotizaciones (Acuerdo 049 de 1990, art. 25) que se cancelan obligatoriamente y con independencia de si el cónyuge que pueda llegar a ser beneficiario labore a su vez y cotice igualmente con el propósito de obtener protección frente a sus propios riesgos. Es notorio, por tanto, que este enfoque descarta también abiertamente la postura censurada del fallador, (que afirmó la incompatibilidad entre la pensión de sobrevivientes y la de vejez, anota ahora la Corte) pues de admitirse ésta, se perdería sin contraprestación ninguna y pese a acontecer la contingencia protegida, el valor, en todo caso importante, de la cotización descontada de la remuneración de un asalariado, así como también del respectivo aporte patronal, contrariándose de paso el principio de eficiencia que corresponde al servicio público de la seguridad social.'... (Sentencia de 24 de enero de 1995). Como inferencia lógica de la ausen- 
cia de la función indemnizatoria del daño, resultante de la pérdida de la vida en la pensión de sobrevivientes, no hay posibilidad jurídica de que el pago que por ese concepto hace la seguridad social, dé lugar a la subrogación por la cual se averigua, lo que permite entender que el fallador desacertó cuando estimó que la pensión era de naturaleza indemnizatoria, y por ello aseveró, equivocadamente, la imposibilidad de la acumulación con la indemnización a cargo del directo causante del hecho dañoso, cuando hizo la estimación del lucro cesante. ${ }^{\text {I }}$

El criterio según el cual la pensión de sobrevivientes no es una prestación de naturaleza indemnizatoria fue ratificado por la Corte en pronunciamientos proferidos durante los años 2012 y 2015 , en los que nuevamente desconoció la facultad de subrogación que le asiste al asegurador de riesgos laborales en contra de tercero causante del daño.

En la sentencia del 2012 la Corte indicó que:

Los beneficios pensionales tienen su origen en los aportes realizados para cada uno de esos riesgos, o en el tiempo de servicios, según sea el caso; y por lo tanto son ajenos a cualquier circunstancia que resulte extraña al respectivo sistema; de suerte que al no haber ningún factor de conexión entre ellos y la actividad de un tercero, no podría estatuir la ley, como en efecto no lo hace, la facultad de repetir en contra de éste, toda vez que esas obligaciones se radican de modo exclusivo en la entidad aseguradora y a nadie más pueden transmitírsele.

Por el contrario, los daños patrimoniales futuros sufridos por los deudos de la persona fallecida a raíz del hecho lesivo, consisten en la pérdida de aquellas contribuciones o utilidades económicas que el finado les habría aportado presumiblemente. Ellos constituyen el lucro cesante y su resarcimiento está condicionado a la demostración, entre otros hechos, de la renta que en promedio recibía el occiso $y$, en particular, de la parte que éste habría destinado de sus propios ingresos a cubrir las necesidades de sus familiares, o a prodigarles una ayuda económica aunque no tuvieran necesidad de ella; es decir que se debe probar la dependencia económica que existía respecto del difunto. De lo anterior se deduce que para el cálculo de los daños patrimoniales futuros resarcibles no interesa que los deudos hayan resultado beneficiados con una pensión de sobreviviente, no solo porque tal atribución se fundamenta sobre un título diferente del hecho lesivo sino porque la existencia de una pensión no tiene ningún nexo de causalidad con las contribuciones patrimoniales o las utilidades económicas que el fallecido habría aportado presumiblemente a sus familiares. 
De hecho, ni siquiera ambos tipos de prestación tienen los mismos destinatarios, aunque a menudo éstos suelan coincidir, porque puede darse el caso de que el afiliado muera sin dejar beneficiarios en el sistema de seguridad social y, no obstante, haya personas legitimadas para reclamar la indemnización civil. O, por el contrario, que no existan perjudicados civiles y, sin embargo, se otorgue la pensión de sobreviviente a quien objetivamente tenga ese derecho. Por lo demás, cualquier persona que resulte lesionada con la muerte de otra puede pedir el resarcimiento de esos perjuicios, en tanto los pruebe; mientras que la pensión solo puede ser recibida por quienes estén taxativamente cobijados por la ley, en estricto orden y proporción, siempre que cumplan los requisitos legales y por el tiempo que la norma determine, independientemente de que la muerte les reporte un perjuicio patrimonial. ${ }^{\text {I }}$

Por último, en sentencia del 20 I 5 , la Corte ratifica que las pensiones de sobrevivientes de origen profesional no tienen un carácter indemnizatorio y además subraya:

Por otro, cuando la disposición señalada (art. I 2 Decreto I 7 I 7 I de I994), alude al 'tercero responsable de la contingencia profesional', es evidente que la empresa demandada no puede ser catalogada como tal, es decir, como tercero, en la medida en que no es ella la que debe asumir la contingencia, esto es, la pensión, habida cuenta que, por ley, le corresponde a la Administradora de Riesgos Profesionales o al patrono.

En ese contexto, la expresión inserta en el artículo memorado ( 2 del Decreto I77 I de i994), alusiva a que la 'administradora de riesgos profesionales podrá repetir, con sujeción a las normas pertinentes', no describen otro condicionamiento distinto a que, en primer lugar, la subrogación debe ser posible atendiendo la naturaleza de la contingencia o prestación que liberaría el recobro; luego, superada esa exigencia, el procedimiento pertinente con miras a la repetición debe responder a la normatividad respectiva que involucra, $v$. gr., la acreditación de las constancias de pago, que el mismo se haya realizado a su destinatario natural o el diputado para receptarlo, etc. En fin, en ese contexto, considera la Corte que la cancelación de la pensión de sobrevivientes no autoriza a la actora a promover recuperación alguna de las sumas canceladas, pues, se reitera, es una obligación 
propia de su función, sin el carácter indemnizatorio proveniente del hecho dañino y por tanto ajeno al tercero causante del perjuicio. ${ }^{\mathrm{I2}}$

\section{Procedencia Jurídica de La Subrogación en RIESgos Laborales}

Pese a la línea jurisprudencial que la Corte ha sentado frente a la improcedencia de la subrogación en materia de riesgos laborales, en mi opinión, jurídicamente es completamente viable, en consideración a lo siguiente:

$\mathrm{El}$ argumento esgrimido por la Corte, según el cual la subrogación es improcedente debido a que las prestaciones derivadas del sistema de riesgos laborales pueden ser acumuladas con la indemnización civil por tener una causa jurídica diferente es, a mi juicio, insuficiente para desvirtuar la procedencia de la subrogación del asegurador, cuando esta ha sido reconocida por el ordenamiento jurídico.

Estimo que, si bien, una y otra provienen de causas jurídicas distintas, lo cierto es que las dos pretenden reparar los perjuicios padecidos por el trabajador o sus familiares producto de un evento ATEP atribuible a un tercero y en esa medida, las indemnizaciones derivadas del sistema de riesgos laborales y de la reparación civil de los perjuicios cumplen la misma finalidad y no debe permitirse su acumulación, pues se estaría generando un beneficio o lucro en favor de la víctima de un evento dañoso. Lo anterior se exacerba cuando el ordenamiento jurídico de manera expresa consagra la figura de la subrogación del asegurador, pues, en ese caso, es mucho más clara la imposibilidad de acumular las dos indemnizaciones.

Además, en línea con la teoría de la compensación del lucro con daño (compensatio lucri cum damno), según la cual si las prestaciones a acumular son consideradas como un beneficio o lucro, debe reducirse la indemnización en un monto proporcional al del dicho lucro, cuando quiera que se demuestre que su causa adecuada ha sido el hecho que también dio lugar al daño, tal y como ocurre en los eventos ATEP atribuibles a la responsabilidad de un tercero.

Es así como, pese a que existen claras diferencias entre la responsabilidad civil y la seguridad social, en últimas las dos disciplinas jurídicas tienen una relación bastante cercana en la medida que todos los daños padecidos por una persona son susceptibles de ser cubiertos a la vez por la responsabilidad civil y la seguridad social.

En esa medida, pese a que el empleador traslade a un asegurador los riesgos profesionales de sus trabajadores, sin duda las prestaciones derivadas de los eventos ATEP tienen una clara naturaleza indemnizatoria, ya que buscan reparar al trabajador o a su familia frente a las consecuencias derivadas del evento 
y, en ese orden, si el ordenamiento jurídico consagra expresamente la facultad de subrogación del asegurador en contra del tercero responsable del evento, de contera las indemnizaciones de la seguridad social y de la responsabilidad civil no podrá acumularse.

Frente a la imposibilidad de acumular las indemnizaciones derivadas de la seguridad social y de la responsabilidad civil, cuando se consagra la facultad de subrogación en favor del asegurador, se pronunció el Consejo de Estado en los siguientes términos: "Cosa distinta sucede cuando el hecho causante del daño es imputable a un tercero distinto del patrono o empleador. En este caso, el único mecanismo que impediría a la víctima acumular la indemnización de perjuicios con las prestaciones obtenidas de la seguridad social sería la subrogación"³.

Ahora bien, dado que la indemnización que reconoce el asegurador en el sistema de riesgos laborales está previamente tarifada por la ley, es perfectamente posible que su cuantía no coincida con la de la indemnización integral de perjuicios a cargo del tercero responsable, razón por la cual, al ejercer la acción de subrogación, y, en consecuencia, ocupar el lugar de la víctima, las pretensiones del asegurador subrogado estarán limitadas al importe de lo pagado (siguiendo los lineamientos consagrados por el artículo ro96 del Código de Comercio) y en el evento que el valor de la indemnización integral sea superior al de las prestaciones otorgadas por el asegurador de riesgos laborales, el excedente deberá percibirlo directamente la víctima y en esa misma línea, si el valor de la indemnización integral por responsabilidad civil es inferior, la subrogación del asegurador estará limitada a dicho monto.

Lo anterior, deja sin piso la consideración de Corte, según la cual, el recobro comporta un beneficio en favor del responsable del siniestro. Por el contrario, el ejercicio de la acción de subrogación garantiza que no quede impune el resarcimiento a cargo del responsable, pues este deberá pagar integralmente la indemnización, según su cuantía, completa o parcialmente a la aseguradora subrogada y como se anotó antes, en el evento que el valor a indemnizar sea superior al importe de lo pagado por el asegurador, el excedente deberá ser sufragado en favor de la víctima. Debe precisarse que la acción de subrogación no comporta una excepción a la carga de probar los perjuicios padecidos por la víctima y, en esa medida, al ocupar el lugar de esta última, el asegurador deberá probar su cuantía y en ningún caso podrá solicitar pura y simplemente el reembolso del importe de lo pagado a los beneficiarios de las prestaciones del sistema de seguridad social, pues como se ha repetido insistentemente, al subrogarse, el asegurador estaría ejerciendo una acción de responsabilidad civil y no una propia del sistema de seguridad social. En esa medida, no sobra advertir que, si 
no existieren beneficiarios para las prestaciones derivadas del sistema de riesgos laborales, es claro que no habría subrogación, pues como es sabido, el pago de la indemnización es el hecho generador del derecho subrogarse.

Otro punto que no comparto de la postura jurisprudencial es que la subrogación del asegurador genera una supuesta transferencia de obligaciones del sistema de riesgos laborales a otra persona, en este caso, al responsable del hecho dañoso. Sin duda, el primer y único responsable por el reconocimiento y pago de las prestaciones derivadas del sistema de riesgos laborales es el asegurador y este, en ningún caso podría pretender liberarse de la obligación de reconocer y pagar las prestaciones a su cargo argumentando que el tercero responsable es el llamado a indemnizar integralmente los perjuicios.

Como es sabido, las ARL están sujetas a un régimen de responsabilidad objetiva, motivo por el cual están obligadas a pagar las prestaciones establecidas en la ley ante un evento ATEP, independiente de cual sea su causa. Por esa razón, me aparto por completo de la postura de la Corte en este punto, pues la figura de la subrogación lo que busca es que el asegurador repita, en ejercicio de la acción de responsabilidad civil que ostentaba la víctima, en contra del tercer causante del daño. En otras palabras, la relación entre la ARL y el beneficiario de las prestaciones derivadas del sistema de riesgos laborales no puede verse alterada, so pretexto de la responsabilidad imputable a un tercero en la ocurrencia del evento ATEP.

Ahora bien, a mi juicio el único argumento jurídicamente válido para negar efectos a la figura de la subrogación en riesgos laborales consagrada en el artículo I 2 del Decreto I 77 I de I 994 es, precisamente, el vicio de ilegalidad que afecta a dicho precepto, teniendo en cuenta que, como se señaló al inicio del presente escrito, en el artículo r 667 del código civil, la subrogación opera en virtud de una norma de rango legal o por convención expresa con el acreedor.

En esa medida, siendo el Decreto I77 I de I994 apenas un acto administrativo, el artículo I 2 está claramente viciado de ilegalidad, en la medida que regula una materia que por expreso mandato del Código Civil está reservado al legislador.

En ese orden de ideas, a mi juicio, la única norma que puede aplicarse en materia de subrogación para el sistema de riesgos laborales es el artículo i roo del Código de Comercio que, como se señaló antes, establece una excepción expresa a la regla general según la cual, la subrogación solamente opera en los seguros de daños, autorizando al asegurador de riesgos laborales para subrogarse en los derechos del asegurado contra las personas responsables del siniestro hasta por el importe de lo pagado. Pero, dicho artículo establece un requisito que hace que en la práctica sea de muy difícil aplicación, pues exige que las partes convengan la subrogación en favor del asegurador. 
Así las cosas, siendo el artículo r roo del Código de Comercio la única norma que, sin estar afectada por vicio de ilegalidad alguno, permite la subrogación del asegurador, se estima conveniente que se promueva una reforma a dicho artículo, de manera que se elimine el requisito de convención entre las partes para que opere la subrogación en riesgos laborales y que, en su lugar, se apliquen todas las reglas generales que sobre la materia regula el artículo rog6 y siguientes del estatuto mercantil.

\section{Bibliografía}

Colombia. Consejo de Estado, Sección Tercera. Sentencia (octubre 3 de 2002). C.P.: Ricardo Hoyos Duque.

Colombia. Corte Suprema de Justicia, Sala de Casación Civil. Sentencia (22 de enero de I99i). M.P.: Eduardo García Sarmiento.

Colombia. Corte Suprema de Justicia, Sala de Casación Civil. Sentencia (3 de septiembre de I99r). M.P.: Pedro Lafont Pianetta.

Colombia. Corte Suprema de Justicia, Sala de Casación Civil. Sentencia (23 de septiembre de I993). M.P.: Pedro Lafont Pianetta.

Colombia. Corte Suprema de Justicia, Sala de Casación Civil. Sentencia (24 de junio de I996).

Colombia. Corte Suprema de Justicia, Sala de Casación Civil. Sentencia (22 de octubre de I998). M.P.: José Fernando Ramírez Gómez.

Colombia. Corte Suprema de Justicia, Sala de Casación Civil. Sentencia (I 2 de mayo de 2000). M.P.: Jorge Antonio Castillo Rugeles.

Colombia. Corte Suprema de Justicia, Sala de Casación Civil. Sentencia (i 8 de mayo de 2005). M.P.: Carlos Ignacio Jaramillo Jaramillo.

Colombia. Corte Suprema de Justicia, Sala de Casación Civil. Sentencia (9 de julio de 201 2). M.P.: Ariel Salazar Ramírez

Colombia. Corte Suprema de Justicia, Sala de Casación Civil. Sentencia (4 de noviembre de 2015).

Colombia. Presidencia. Decreto (I77 I de I994), sobre reglamentación parcial del Decreto I 295 de I994. 